\title{
Sujeito e seus (des)caminhos de pedras: reflexões sobre o discurso hegemônico relacionado a droga e a drogadição
}

\author{
Subject and his stones reflections on the hegemonic discourse related to drug and drug \\ addiction
}

Edna Linhares Garcia ${ }^{1}$, Mauriceia Eloisa Moraes ${ }^{1}$, Júlia Souza de Moraes ${ }^{1}$, Vitoria Merten Fernandes $^{1}$, Jane Dagmar Pollo Renner ${ }^{1}$

${ }^{1}$ Universidade de Santa Cruz do Sul, Santa Cruz do Sul, RS, Brasil.

\author{
Submissão: 07/09/2016 \\ Aceite: 05/10/2016 \\ edna@unisc.br
}

\section{RESUMO}

Justificativa e Objetivos: Este trabalho apresenta reflexões que tem por objetivo evidenciar e problematizar os discursos relacionados a drogadição, bem como as práticas de Atenção e Cuidado daí decorrentes. Métodos: Trata-se de um recorte das análises dos dados da pesquisa 'A Realidade do Crack em Santa Cruz do Sul', realizada com base teórico-metodológica de análise de sentidos produzidos nos discursos, a partir de 100 entrevistas com usuários de crack do município e 100 familiares de usuários. Resultados: O tratamento dos dados possibilitou a elaboração de marcadores para sistematização das análises, entre os quais elegemos os seguintes para o presente artigo: Práticas Discursivas: Crack como Epidemia; Práticas de Saúde: O Cuidado a Partir das Políticas Públicas; Processo de Desnaturalização de Discursos Vigentes. A partir desses marcadores, os discursos midiáticos e de pesquisadores contemporâneos são problematizados, de onde decorre a constatação de discursos reducionistas e práticas excludentes, promotoras de relações de sofrimento que despotencializam usuário e família. Conclusão: Apontamos para a necessidade de práticas de cuidado mais humanizadas que sustentem a singularidade do sujeito na construção de projetos de vida para além da droga.

DESCRITORES: Drogas Ilícitas. Relação Pesquisador-Sujeito. Políticas Públicas.

\begin{abstract}
Background and Objectives: This paper presents reflections which aims to highlight and problematize the speeches about drug addiction, as well as the attention and care practice resulting therefrom. Methods: It is a cut of the analysis of the survey data "The Reality of Crack in Santa Cruz do Sul", performed with theoretical and methodological basis of analysis of meanings produced in speeches, from 100 interviews with crack users from the municipality and 100 users' families. Results: The data analysis enabled the development of markers for systematization of analysis, from which we elected the following for this article: Discursive Practices; Crack as Epidemic; Health Practices: care from the public
\end{abstract}


policies; Process of denaturalization of the current speeches. From these markers, the media speeches and contemporary researchers are problematized, where we found reductionist discourses and exclusionary practices, promoting suffering relationships that don't potentiate users and families. Conclusion: We point to the need for more humane care practices that support the uniqueness of the subject in the construction of life projects beyond the drug addiction.

KEYWORDS: Street Drugs. Researcher-Subject Relations. Public Policies.

\section{INTRODUÇÃO}

"Nada mudou na minha vida depois que comecei o crack". "Como assim?", indagou a pesquisadora surpresa com o discurso de seu entrevistado que, diferente de tantos outros, não demonizava o crack. A objetividade com que a frase foi repetida nos anunciava um encontro com revelações de verdades e realidades que passavam à margem dos discursos hegemônicos e midiáticos.

Assim, com voz serena e sorriso incrédulo João, 14 anos, estudante do $2^{\circ}$ ano do ensino fundamental falava sobre sua história de vida e sobre as relações com as quais se deparou ao longo dela. Um discurso que evidenciava vazios, medos, ideais e desejos a partir de uma fala serena, acompanhada de um sorriso incrédulo, olhar fixo e tristonho que enunciava o longo percurso de cocaína, desde os nove anos de idade.

Neste cenário, é preciso que nos ocupemos em problematizar os caminhos que se apresentam para estes jovens. Assim, apresentamos reflexões a partir de um recorte dos dados da pesquisa "A realidade do crack em Santa Cruz do Sul”, a qual buscou evidenciar e

problematizar o contexto cultural, histórico, social e econômico dos sujeitos participantes. Para fins de conhecimento e contextualização, é importante enfatizar que a amostra foi composta prioritariamente por homens usuários de crack (87\%); o início do uso de drogas se deu entre os 10 e 15 anos de idade (62\%); os níveis de escolaridade eram baixos, tendo $51 \%$ ensino fundamental incompleto; além disso, encontravam-se geralmente em situação de emprego informal ou precário no que concerne aos direitos trabalhistas - mesmo antes do uso de crack. Esta realidade é detalhada na publicação "(Re)conhecendo o perfil do usuário de crack de Santa Cruz do Sul". ${ }^{1}$

A vivência de João exemplifica a realidade com a qual nos deparamos quando nos dispomos a escutar para além dos discursos relacionados a droga, ou seja, quando nossa escuta alcança o sujeito e os múltiplos vieses que o constituem, seja nas narrativas das entrevistas analisadas na presente pesquisa, ou no encontro com o cotidiano dos serviços. 
Desta forma, não é raro que profissionais da saúde, da educação, da assistência social, entre tantos outros, que se proponham a refletir sobre o cenário que constitui a vida dos jovens, especialmente dos jovens usuários de crack, façam emergir a pergunta: $\mathrm{O}$ que fazer diante de tantos descaminhos produzidos ou reforçados pelos encontros tão precoces com as drogas $?^{2}$

Ao se tratar de questões complexas, perpassadas por fatores históricos, sociais, políticos, culturais, econômicos, adentra-se inevitavelmente o campo das políticas públicas e da intersetorialidade, tais como, saúde, educação, assistência social, a partir das quais programas, ações e intervenções são elaborados e propostos, com objetivo de proporcionar respostas aos problemas decorrentes do uso abusivo de drogas. Quando tais questões abrangem a infância e a adolescência - e quase sempre o fazem - maior a cautela e a prudência necessárias, já que nos referimos a sujeitos numa dimensão da vida mais vulnerável.

O discurso hegemônico contemporâneo oferece uma realidade onde o crack ocupa um lugar de vilão responsável pelas "desgraças atuais", o que ocasiona um sentimento de caos social generalizado. O Jornal Folha de São Paulo publicado em 2014, ressalta que morrem mais vítimas da epidemia do crack do que nas demais epidemias virais somadas e que pelas amostragens municipais é possível inferir que $1 \%$ da nossa população está dependente da droga, isto significa que são quase dois milhões de brasileiros.

A partir de enunciados como este, em nome do crack, tem-se constituído práticas que sustentam e são sustentadas por um discurso ideológico que, enquanto o toma como “o problema social”, desestruturador da família, das relações sociais e da paz, menospreza e torna enturvadas perguntas que remetem especialmente a investigações sobre como se instaurou esse fenômeno na realidade atual. Os dados e análises da pesquisa revelam que o fenômeno não pode ser visto e percebido apenas enquanto uma estatística, pois dessa forma apenas promove a demonização do crack. Na verdade, estes dados devem convocar para uma análise dos fatores implicados buscando compreender esta 'epidemia'.

Estes discursos perpassam o contexto da família e intensificam o sofrimento por meio da culpabilização frente ao fato de ter um de seus membros usuário de drogas. ${ }^{3}$ Do mesmo modo, evidenciam-se discursos nos quais a droga ocupa este lugar da culpa pela infelicidade vivenciada, expressando um ciclo de discursos caracterizados pela angústia e 
pela intensidade de tratar a droga como o sujeito da relação. Nos trechos que seguem é possível evidenciar esta conotação:

"A gente fica um pouco envergonhado porque a família da gente não é dessas coisas, e a gente quer que ele se salve." (familiar 1 de usuário de crack)

"Após as drogas mudou muita coisa, muita coisa. Nunca mais eu tive paz, paz não tenho. É só incomodação, incomodação, todo mundo revoltado..." (Familiar 2 de Usuário de Crack)

Entender o crack como vilão não é uma verdade absoluta para todos. A abordagem da mídia sobre o tema tem um apelo de interesses, investindo na transmissão de um discurso social aterrorizante, ocasionando uma alienação relacionada aos questionamentos sociais e econômicos envolvidos no crescente número de usuários de drogas. ${ }^{4}$

\section{MÉTODOS}

O presente artigo configura um recorte da pesquisa "A realidade do crack em Santa Cruz do Sul", que reúne investigações de natureza quantitativa, bem como qualitativa, descritiva e exploratória e seus dados analisados na perspectiva da análise da produção de sentidos e os dados quantitativos tratados pelo programa Statistical Package for the Social Sciences (SPSS) versão 20. A pesquisa foi submetida ao Comitê de Ética em Pesquisa da Universidade de Santa Cruz do Sul, aprovado sob protocolo/CAAE 11871213.0.0000.5343.

A abordagem qualitativa da realidade viabiliza uma compreensão da subjetividade, das particularidades nas relações, dos fenômenos na dimensão individual, evidenciando, em acordo com Minayo (2010), a existência de um nível da realidade não passível de mensuração, nem redutível a operacionalizações de variáveis. $^{5}$ A perspectiva construcionista da realidade entende que o conhecimento resulta de uma construção social, da interação humana datado de um certo período histórico, isto é, o conhecimento se produz na coletividade e na intersubjetividade/interpessoalidade. ${ }^{5}$

A escolha pelo método deve-se ao fato de se tratar de um tema que nos instiga a refletir sobre diversos discursos produzidos neste âmbito, os quais se reinscrevem continuamente no nosso cotidiano e produzem modos de ser e estar implicados no sofrimento e adoecimento nos jovens do contemporâneo. Esta metodologia aguça nossa 
imaginação e convoca a participar ativamente dos processos de transformação social, como assinalam Spink e Frezza (2000). ${ }^{6}$

Inicialmente, realizamos a organização das 100 entrevistas dos usuários, seguida de intenso contato com o material em análise que, conforme Bardin (1977), através da "leitura flutuante", produzimos hipóteses ou questões norteadoras, sustentadas em teorias reconhecidas. ${ }^{7}$ Após essa primeira fase, exploramos o material, dando visibilidade aos sentidos em relação às questões suscitadas e significativas para a problemática pesquisada, configurando como marcadores aquilo que mais caracteriza os discursos. Assim, os dados foram transformados de forma organizada e apresentados em categorias, que possibilitam a descrição das características dos discursos dos sujeitos entrevistados. Dentre as categorias, elegemos para o presente artigo aquela nomeada de "culpabilização e vergonha". Buscamos neste recorte, refletir sobre os discursos que sustentam a produção desses sentidos, ou seja, que perpassam o contexto da família e intensificam o sofrimento por meio da culpabilização e da vergonha, frente ao fato de ter um de seus membros como usuário de drogas. A partir dessa categoria elaboramos os seguintes marcadores: Práticas discursivas: crack como epidemia; Práticas de saúde: o cuidado a partir das políticas públicas; Processos de desnaturalização de discursos vigentes. Em torno desses marcadores evidenciamos o discurso hegemônico veiculado pela mídia, de modo a tensioná-lo a partir de teóricos contemporâneos, os quais desestabilizam a tendência à redução ou superficialização desta complexa questão que é a droga e a drogadição no contexto contemporâneo.

\section{RESULTADOS}

\section{Práticas Discursivas: Crack como Epidemia}

Este entendimento do crack enquanto vilão responsável por diversas problemáticas sociais encontra na mídia sua sustentação e proliferação, o que influencia diretamente nas práticas e intervenções junto às pessoas que usam drogas. Tais ações, em sua maioria, buscam estagnar o uso do crack sem levar em consideração a necessidade de compreender as relações de verdade, saber e poder que as sustentam. Desta forma, a tendência de não vislumbrar os diferentes fatores atravessados na questão das drogas contribui densamente 
para a disseminação e intensificação do uso de crack e, especialmente, inviabiliza a busca de cuidado na rede de saúde.

As manobras proibicionistas são legitimadas quando os meios de comunicação convencem a população da existência de uma epidemia, representando um retrocesso para construção das redes de cuidado em saúde mental para pessoas que usam drogas e a justificativa de ações policiais repressoras altamente violentas pautadas em uma visão simplista e acrítica. ${ }^{8}$

O entendimento de Gorgulho (2011) segue nesta mesma direção ao considerar que a melhor forma de abordar a temática das drogas é o diálogo e a educação, sendo que a proibição apenas produz uma população obediente, seguidora de ideologias sem questionálas, aceitando o que lhe é imposto sem críticas. ${ }^{9}$ A questão deve ser expandida para movimentos de reflexão e debates sobre promoção de saúde e cuidado integral e envolver a educação e supervisão técnica dirigidas aos profissionais da saúde. ${ }^{10}$

Em relação ao crack, são produzidos discursos simplistas e a-históricos que estabelecem uma relação causal e linear entre usuários de drogas - sejam estas crianças, adolescentes ou adultos - e transtornos de conduta, violência, delinquência, marginalidade, etc. Em decorrência, assistimos a produção de práticas carregadas de preconceitos e exclusões, que negam as realidades distintas e desconsideram a possibilidade destas comporem o mesmo contexto social.

Em razão desta tendência reducionista e superficial com que são tratadas as questões que abrangem essa temática, Conte (2003) ressalta a perda da possibilidade do reconhecimento das "as nuances singulares de como a droga pode instalar-se em qualquer quadro clínico", conhecimento este valioso para operar na integralidade do cuidado. ${ }^{11}$

$\mathrm{Na}$ mesma direção, com o intuito de sinalizar os riscos dos discursos “demonizantes”, Santos (2010) chama atenção para prejuízos às conquistas da luta antimanicomial: ${ }^{12}$

a falta de debates democráticos sobre o assunto tem capitalizado discursos de cunho ideológico, deixando a população à mercê de um discurso reducionista sobre o assunto, o que incide no cotidiano da rede de cuidados de pessoas que usam drogas, fragilizando e desqualificando a assistência. Além disso, este discurso coloca todas as pessoas que usam drogas ilícitas num lugar marginal, como bode expiatório dos problemas sociais, desconsiderando quaisquer outros aspectos da contemporaneidade relacionados ao tema. ${ }^{12}$ 
Este panorama reflete, de maneira direta e indireta, outra tendência da sociedade contemporânea, tão interligada à primeira, a saber, a tentativa incessante de eliminação do sofrimento e do mal-estar, estes intrínsecos ao laço social e à vida em sociedade.

Freud (1921) já lembrava que a reação mais comum frente ao mal-estar é a tentativa de sua imediata supressão. ${ }^{13}$ Birman (2005) retoma esta proposição ao pontuar que na sociedade atual, marcada pela performance e por uma imagem ideal significa na juventude, na magreza e no imediatismo, os medicamentos são instrumentos profícuos para anestesiar sensações e sentimentos, servindo ao imperativo de não sentir/manifestar tristeza, fraqueza, angústia, o que poderia gerar situações de estigma e exclusão. ${ }^{14}$

Este fato vem se tornando cada vez mais presente em diversos contextos da vida em sociedade. A salvação a partir da medicalização configura proposta corrente, seja na escola, na família, no trabalho. Observamos a recorrência da busca de sedativos, analgésicos e estimulantes para enfrentar, por exemplo, as questões do mundo do trabalho e da escola, cenários de intensa competitividade, onde a pressão por resultados definidos por metas cada vez mais inatingíveis conduzem a vivências de muita solidão. Contudo, ainda que esta busca por anestésicos e estimulantes seja uma demanda atual, notamos que o consumo intenso dessas drogas não se constitui como foco do debate necessário, pois o enfoque dado às drogas ainda é fortemente limitado a conceitos como licitude, moralidade, criminalidade.

As drogas consideradas lícitas estão asseguradas por diferentes discursos que envolvem conotações de poder e saber garantidos pela neurociência, que nos prometem um futuro onde alcançaremos uma felicidade plena, libertos da angústia estrutural e estruturante, inerente à condição humana.

\section{Práticas de Saúde: O Cuidado a Partir das Políticas Públicas}

As políticas públicas têm como objetivo garantir direitos da população a uma vida de qualidade seja na dimensão individual ou coletiva, constituindo um recurso de intervenção do Estado, que produz modos de ser e estar no mundo. ${ }^{15}$ Nesta perspectiva, o cotidiano do trabalho em saúde tem os seus processos de trabalho compreendidos como produtos e produtores de modos de cuidar, que podem promover vínculos por meio dos quais a saúde pode ser potencializada. Do mesmo modo, podemos entender que os 
procedimentos em saúde nem sempre são promotores de cuidado, especialmente quando não implicam momentos de estímulo à autonomia do sujeito para gerir sua vida. ${ }^{16}$

A proposta da Reforma Psiquiátrica Brasileira, ratificada em termos legais pela Lei 10.216/2001, indica novas diretrizes para o trabalho em saúde mental que visam à reestruturação dos modelos de atenção e cuidado para lidar com o sofrimento psíquico, baseados na garantia dos direitos humanos, intrínsecos a condição de todos os cidadãos, por meio da atenção integral e descentralizada para a comunidade e reinserção social e familiar do portador de sofrimento psíquico, estabelecendo serviços substitutivos para o cuidado destas pessoas, fundamentado no cuidar em liberdade. ${ }^{17,18}$ Porém, desde sua implementação sabemos dos entraves e desafios encontrados para a efetivação dessas práticas.

Tal realidade também é facilmente encontrada nas políticas públicas de atenção voltadas aos usuários de álcool e outras drogas, uma vez que, em tempos anteriores, propagaram-se ações de saúde permeadas pela lógica da exclusão e anulação desses sujeitos do meio social, sob o pretexto da urgência de tratamento. Como podemos reconhecer no próprio texto da Política Nacional para a Atenção Integral a Usuários de Álcool e Outras Drogas, "no vácuo de propostas concretas, e na ausência do estabelecimento de uma clara política de saúde voltada para este segmento, surgiram no Brasil diversas 'alternativas de atenção' de caráter total, fechado e tendo como único objetivo a ser alcançado a abstinência". 19

Romanini e Roso (2012) afirmam que ações de repressão e tratamentos centrados em aspectos biológicos e curativos, na abstinência, estão relacionados a criminalização do usuário de drogas, atrelada ao discurso antidrogas que sustenta um movimento de guerra às drogas, vigente na sociedade brasileira, e também em outros países. ${ }^{18}$ Para os autores, a Política Nacional para a Atenção Integral a Usuários de Álcool e Outras Drogas (2003) tenta romper com estas abordagens reducionistas e criminalistas, propondo uma compreensão complexa e histórica acerca do uso de drogas, englobando aspectos individuais, sociais, psicológicos, econômicos e políticos. ${ }^{20}$

Assim, fica evidente a necessidade de formação e fortalecimento de uma ampla rede de atenção aos usuários de drogas e seus familiares, que não se restrinja às intervenções psiquiátricas e jurídicas, ou ainda, ao âmbito da saúde. ${ }^{19}$ Neste sentido, a Política Nacional para a Atenção Integral a Usuários de Álcool e Outras Drogas (2003) pretende abordar a 
complexidade relativa ao uso de drogas e compromete-se com ações de redução dos danos, garantindo exercício dos direitos e ainda, aposta em mudanças no cuidado aos usuários de drogas afirmando que a sociedade,

disponibiliza uma extensa gama de políticas potenciais, e a sua inventividade e alcance estão em um processo de expansão contínua, sendo então possíveis outras formas de produzir novas possibilidades de vida para aqueles que sofrem devido ao consumo de álcool e drogas. Tal produção não ocorre somente por leis, planos ou propostas, e sim pela sua implementação e exercício no cotidiano dos serviços, práticas e instituições. ${ }^{19}$

Esta perspectiva nos convoca, enquanto atores sociais, a contribuir para a construção de novos manejos de cuidado, pautados especialmente na valorização e na dimensão singular de cada sujeito, atentando para os diversos fatores que o constituem.

\section{Processo de Desnaturalização de Discursos Vigentes}

Apostando nesta possibilidade de construção do cuidado, apresentamos algumas assertivas que podem ser apropriadas para a reflexão sobre a temática do uso de drogas, principalmente quando envolve crianças e jovens.

Inicialmente, importa perceber e refletir sobre a dinâmica social que se estabelece a partir do mal-estar contemporâneo. Produz-se uma demanda por tratamento medicamentoso com vistas a resultados imediatos. As drogas lícitas respondem à lógica de uma sociedade de consumo, que se sustenta na medida mesma da suspensão do pensamento e da reflexão crítica. Assim, as drogas lícitas entram em cena frente a qualquer mal-estar, de modo a evitar processos de pensamento ou tratamentos que exijam maior envolvimento afetivo, pois implicam em trabalho psíquico e subjetivo. Assim, a droga aparece como recurso que permeia os mais diversos grupos e espaços sociais.

Importante ressaltar que toxicomanias e o uso de drogas não são sinônimos, assim como não é regra que todo usuário desenvolva uma toxicomania. Torna-se necessário atentar para o lugar que as drogas ocupam na vida de cada sujeito e de como se apresentam singularmente em cada processo. É fundamental o conhecimento desses contornos por parte dos profissionais, não somente da área da saúde, mas também dos educadores, entre outros, 
para que não incorram no erro de tomar um pelo outro, ou seja, de trabalhar com o usuário de drogas como se ele fosse um toxicômano e vice-versa.

Neste sentido, Torossian (2002) explica que existem dois grupos distintos quando se refere às drogas. ${ }^{21} \mathrm{O}$ primeiro grupo, formado por indivíduos que fazem o uso de drogas e mantém outros interesses e atividades como lazer, esporte, trabalho, educação, etc., e que são considerados como usuários não exclusivos. Já o segundo grupo é composto por sujeitos que fazem o uso intenso de drogas, estabelecendo uma relação de exclusividade com estas. Desse modo, configura-se uma situação na qual não ocorrem manifestações de interesses por nada além da própria droga sendo, por isso, considerados usuários exclusivos ou toxicômanos.

Neste caso, estamos na dimensão de um uso abusivo da droga, provocador de sofrimento, anulador da potência de vida do sujeito. Sua vida passa a ser ditada neste apelo e por isso mesmo merece um tratamento especializado, reconhecendo-se primeiramente o sofrimento deste sujeito que, no momento, somente consegue "dizer de si" a partir de sua relação com a droga.

Outro ponto importante refere-se ao fato de não tomar a adolescência numa relação direta e causal com os processos de drogadição. É imprescindível refletir sobre a questão da adolescência considerando o contexto da atualidade, classe social, fatores econômicos, culturais, para finalmente compreendê-la como um processo cultural que, no caso de nossa cultura, configura um momento da vida onde os processos de subjetivação são permeados por muitos conflitos de diversas ordens, mas que não necessariamente indicam psicopatologias.

Contudo, a adolescência desperta constantes preocupações por parte dos pais, educadores e da sociedade em geral, por entendê-la como condição propícia ao envolvimento com as drogas ilícitas. Desta forma, torna-se fundamental não estabelecer uma relação de causalidade entre drogadição e adolescência, mas sim entender o contexto no qual a adolescência se constitui na modernidade. Reconhecemos que no contexto do consumismo e do imediatismo da atual sociedade capitalista, a droga se constitui como um meio para atender aos imperativos de felicidade que balizam a sociedade contemporânea, tão destituída de projetos sociais compartilhados. Logo, não há como desprezar este contexto nas análises sobre o uso do crack pelos jovens. 
É importante contar com conjunturas de sustentação familiar, escolar, comunitária, que produzam vínculos afetivos seguros para que o sujeito possa elaborar e conviver com todas as transformações dessa dimensão da vida. ${ }^{22}$ As referências identificatórias que sustentam e suportam o processo de subjetividade dos adolescentes são aquelas que estão dispostas a investirem afetivamente na relação com estes sujeitos, para além de ser pai ou mãe, também outros que desempenhem a função de cuidador, de protetor e de limitador.

Não há como negar que uma das dificuldades no campo da educação, uma pedra no caminho de pais e educadores, tem sido a fragilidade no exercício das funções de autoridade e de proteção e de interdição, circunstâncias que caracterizam a nossa contemporaneidade. Reconhecemos que a presença de limites não necessariamente concerne a uma boa educação e assistimos a um silenciar das referências simbólicas que organizam as interdições fundamentais, produzindo um contexto no qual a palavra perde seu poder simbólico.

\section{DISCUSSÃO}

Diante dessas análises a partir dos discursos vigentes sobre a droga e a drogadição, ressaltamos algumas considerações. A primeira é que se torna imprescindível que, do lugar de profissional que trabalha direta ou indiretamente com crianças e jovens, esta temática seja problematizada, refletindo sobre aspectos da contemporaneidade, sob o risco de não se compreender as mais diversas dimensões que compõem o comportamento do uso do crack e de outras drogas. Isto significa realizar um esforço para abandonar o discurso dominante e suas práticas excludentes, que despotencializam os sujeitos na medida em que enlaçam um caráter biologicista e moralista aos seus sentimentos e manifestações, tomando a todos como problemáticos, violentos e marginais.

Os prejuízos trazidos à sociedade pelos discursos moralistas e aterrorizantes veiculados em campanhas ameaçadoras, as quais qualificam igualmente todos os tipos de drogas, deixam desprotegida toda uma população de crianças e de adolescentes, uma vez que não aliam informações nem estímulos para construírem projetos de vida, para fazerem escolhas e assumirem compromissos com autonomia. 
A postura dos profissionais precisa estar pautada em uma dimensão crítica da realidade, tenha esta um cenário de crack ou de qualquer outra droga, mesmo as consideradas lícitas. Como agentes de processos de educação, saúde, cultura, inserção social, cabe-lhes problematizar os discursos cristalizados, evitando que as relações de poder se estabeleçam em estado de dominação. Dessa forma, ampliará a capacidade de transformação, valorizando a diversidade dos caminhos que podem levar à construção de valores como cidadania, ética e alteridade.

Consideramos que, se há um movimento de manutenção de estigmas, de preconceitos, calcados no discurso ideológico vigente, há também sempre a possibilidade de um espaço de resistência. Esta opera no sentido de fazer frente às práticas reducionistas e de problematizar o papel de cada sujeito em sua relação com os outros, com a cidade, com o mundo, com os problemas sociais, convocando-o a implicar-se nesse processo de reflexão e ação.

Como profissionais da saúde, por exemplo, cabe-nos a problematização dos discursos vigentes, que (re)produzem a tendência, ainda muito expressiva, das solicitações/ordens de internação psiquiátrica para jovens que usam drogas. Ademais, necessitamos construir junto com o jovem um conjunto de ações que seja do seu interesse, focando na promoção de saúde seja no posto de saúde, nas escolas, em oficinas terapêuticas, em grupos de adolescentes, ou ainda, contando também com outros espaços e serviços que o município oferece, como serviços de convivência, aulas de instrumentos musicais, de artesanato, teatro, línguas, etc.

A escola pode dar espaço para as crianças e os adolescentes expressarem suas ideias, a partir de trabalhos artísticos (música, dança, desenho, pintura), de espaços de discussão e diálogo sobre temas que lhes instigam, valorizando assim o saber construído por eles. Em decorrência, ajuda-os a construir formas de enfrentamento dos problemas da vida, ou seja, sentimentos, ideias, valores que possam lhes auxiliar no momento de enfrentar situações difíceis em contexto familiar ou na comunidade. Estes exemplos de formas-ferramentas de intervenção que sustentam a integralidade do sujeito e respeitam sua autonomia, excluem a produção do sentido que demoniza o uso de drogas e que propõe sua utópica extinção - utópica considerando que nunca houve uma sociedade sem indício do uso de alguma substância química geradora de estados alterados de consciência. Esta 
perspectiva melhora a qualidade de vida das crianças e dos jovens brasileiros propiciando espaços de promoção de saúde.

Freud (1921/2011) postulou que, seja no viés individual, seja no campo das comunidades, não há psicologia que não seja social. ${ }^{11}$ Isto é, não há sujeito que não esteja implicado com o laço social e a sociedade que, por sua vez, somente se constitui a partir das criações dos sujeitos enquanto atores sociais. Nesse sentido, apontamos que esta pesquisa tem buscado - através da publicação de seus dados, da organização de espaços de interação e discussão sobre a temática e, ainda, na articulação com outros setores da universidade e serviços do município - construir e fortalecer redes que contribuam para as transformações. Tais objetivos se assentam na escuta dos sujeitos para elaboração de propostas de ação/intervenção. Estes trabalhos podem ser acessados em suas versões online. ${ }^{24,25}$

Nesta perspectiva, este grupo da pesquisa articula ações, tais como o "Fórum de Discussão sobre Drogas na Contemporaneidade: caminhos de prevenção”. Este objetiva a apresentação dos dados da pesquisa aos mais diversos setores da sociedade e a constituição de um espaço de diálogo, visando à prevenção ao uso de drogas e promoção da saúde, dirigido aos estudantes (crianças e adolescentes) da rede de ensino municipal e estadual da região, bem como pais, professores e profissionais da saúde, assistência social, direito, entre outras.

A partir das atividades do Fórum, foram criadas outras ações de prevenção ao uso de drogas e promoção da saúde no ambiente escolar. Os encontros acontecem em espaços cedidos nas escolas por meio da metodologia de rodas de conversas com professores, pais e estudantes de todas as idades (separadamente), de modo que cada um desses públicos encontra um ambiente sem repressão para falar, ouvir, ser ouvido e se escutar. Neste trabalho, entendemos que tais intervenções são facilitadoras de momentos para reflexão e desconstrução de práticas sociais cristalizadas e discursos ideológicos submersos em valores morais sustentados por relações de poder e saber hegemônico.

Para finalizar, vale recordar que nenhuma ação é neutra em si mesma, que a imparcialidade é uma condição ilusória. Logo, não podemos abrir mão do caráter político de nossas in(ter)venções. Na medida em que sustentamos uma posição ética, em defesa da singularidade e da alteridade do sujeito, neste mesmo instante adentramos inevitavelmente 
o campo político, costurado por diversas lógicas de poder e saber, que por vezes facilitam e noutras dificultam possibilidades e desejos de avançar. Portanto, o caminho continua sendo longo, repleto de desafios, mas isso não se torna impedimento para a retirada de pedras encontradas nos caminhos.

As reflexões apresentadas neste artigo convocam pais, profissionais, jovens, sonhadores e muitos outros que somos, num esforço conjunto e comprometido, a escolher a posição ética a partir da qual nos situamos frente ao sujeito e sua existência. Tal posição requer pensar para além da droga, desconstruindo ideologias que se proliferam pelos mais variados discursos, abrindo possibilidade de narrativa singular para a história de sujeitos como João, que nos convoca a escutar e compreender usuários de drogas como cidadãos atravessados não apenas pela relação com a droga, mas por uma história de vida constituída por uma lógica social, histórica e política. 


\section{REFERÊNCIAS}

1 - Garcia EL, Araújo BR, Zacharias DG. Recaídas na drogadição: uma via para (re)pensar a atenção à saúde. Saúde Debate 2013; 37 (n especial): 137-146.

2 - Amaro V, Fernández J, González M, et al. Consumo de alcohol en niños y adolescentes: Una mirada desde el tercer nivel de atención. Arch Pediatr Urug [Internet] 2016 [citado 2016 nov 28]; $87 \quad$ (Suppl 1): S40-S47. Disponível em: http://www.scielo.edu.uy/scielo.php?script=sci_arttext\&pid=S1688$12492016000500006 \& \operatorname{lng}=\mathrm{es}$.

3- Armendáriz GNA, Alonso Castillo MM, Alonso Castillo BA, et al. La Familia Y El Consumo De Alcohol En Estudiantes Universitarios. Cienc enferm 2014, 20 (3): 109-118. http://dx.doi.org/10.4067/S0717-95532014000300010

4- González LI, Tumuluru S, González-Torres MA, et al. Cocaína: una revisión de la adicción y el tratamiento. Rev Asoc Esp Neuropsiq 2015, 35 (127): 555-571.

5- Minayo MCS. Análise qualitativa: teoria, passos e fidedignidade. Ciênc saúde coletiva 2012; 17 (3): 621-626. http://dx.doi.org/10.1590/S1413-81232012000300007

6 - Spink MJP, Frezza RM. Práticas discursivas e produção de sentidos: a perspectiva da Psicologia Social. In: SPINK, M. J. (org.). Práticas discursivas e produção de sentidos no cotidiano: aproximações teóricas e metodológicas. $2^{\mathrm{a}}$ ed. São Paulo: Cortez, 2000.

7- Bardin L. Análise de conteúdo. Lisboa: Edições 70, 1977.

8- Lancetti A. Desmistificação da existência de epidemia de álcool e outras drogas e medidas higienistas. In: Conselho Federal de Psicologia. Drogas e Cidadania: em debate. Brasília: CFP, 2012.

9- Gorgulho M. Drogas e Sociedade. In: Conselho Regional de Psicologia da $6^{\text {a }}$ Região (Org). Álcool e Outras Drogas. São Paulo: CRPSP, 2011.

10- Calderón-Romero EA, Cáliz-Romero NE. Juventud y universidad: sujetos y escenarios para el debate crítico y autorreflexivo sobre el consumo de sustancias psicoactivas de uso legal e ilegal. Rev Gerenc Polit Salud 2015, 14 (28): 123-141. https://dx.doi.org/10.11144/Javeriana.rgyps18-28.juse 
11- Conte M. A clínica psicanalítica com toxicômanos: o "corte \& costura" no enquadre institucional. Santa Cruz do Sul: Edunisc, 2003.

12- Santos LMB. Diferentes olhares sobre o cuidado de pessoas que usam droga. Conselho Regional de Psicologia do Rio Grande do Sul (CRPRS). Porto Alegre, 2010.

13- Freud S. (1921) Psicologia das massas e análise do eu. In: Sigmund Freud - Obras Completas, vol. 15. São Paulo: Companhia das Letras, 2011.

14 - Birman J. Diagnóstico da contemporaneidade. In: Junior AM., Tedesco, S.; Kupermann, D. (Orgs). Polifonias: Clínica, Política e Criação. Rio de Janeiro: Contra Capa, 2005.

15- Foucault M. Nascimento da Biopolítica. Editora Martins Fontes. São Paulo, 2007

16- Merhy EE. O ato de governar as tensões constitutivas do agir em saúde como desafio permanente de algumas estratégias gerenciais. Ciênc saúde coletiva 1999; 4 (2): 305-314. http://dx.doi.org/10.1590/S1413-81231999000200006

17-Brasil. Lei Federal $n^{\circ}$ 10.216, de 06 de abril de 2001. Dispõe sobre a proteção e os direitos das pessoas portadoras de transtornos mentais e redireciona o modelo assistencial em saúde mental. Brasília, 2001.

18- Ministério da Saúde (BR). Reforma psiquiátrica e política de saúde mental no Brasil. Documento apresentado à Conferência Regional de Reforma dos Serviços de Saúde Mental: 15 anos depois de Caracas. OPAS. Brasília: Ministério da Saúde, 2005.

19- Ministério da Saúde (BR). A Política do Ministério da Saúde para atenção integral a usuários de álcool e outras drogas. Secretaria Executiva, Coordenação Nacional de DST e Aids. - Brasília: Ministério da Saúde, 2003.

20- Romanini M, Roso A. Media and crack: promoting health or reinforcing relations of domination? Psicol Cienc Prof 2012; 32 (1): 82-97. http://dx.doi.org/10.1590/S1414$\underline{98932012000100007}$

21- Torossian SD. A construção das toxicomanias na adolescência: travessias e ancoragens. Santa Cruz do Sul: EDUNISC, 2002.

22- Cabanillas-Rojas W. Factores de riesgo/protección y los programas preventivos en drogodependencias en el Perú. Rev perú med exp salud publica [Internet] 2012, 29 (1).

Disponível em: <http://www.scielo.org.pe/scielo.php?script=sci_arttext\&pid=S1726$46342012000100016 \& \operatorname{lng}=e s \& n r m=i s o>$. 
23- de Araújo BR, Zacharias DG, Garcia EL. O crack em redes discursivas: evidenciando concepções e problematizando práticas de enfrentamento. Rev Jovens Pesq 2013; 3 (1): 97 108. http://dx.doi.org/10.17058/rjp.v3i1.3572

24- Garcia EL, Zacharias DG, Winter GF, et al. conhecendo o perfil do usuário de crack de Santa Cruz do Sul. Barbarói 2012; 1 (36): 83.

25- Garcia EL, Zacharias DG, Petry EL, et al. Entre a alienação de familiares de usuários de crack e os riscos do pesquisador. Barbarói 2013; (39):13-35. Disponível em: http://pepsic.bvsalud.org/scielo.php?script=sci_arttext\&pid=S0104$\underline{65782013000200002 \& \operatorname{lng}=p t \& n r m=i s o .}$ 